\title{
The Present Situation and Creative Significance of the Development of Chinese Picture Book Teaching
}

\author{
Wang Shuang ${ }^{1}$ and Lei Bo ${ }^{2}$ \\ ${ }^{1}$ Teachers' College, Xi'an University, 710065 \\ ${ }^{2}$ School of Preschool Education, Xi'an University, 710065
}

Keywords: Native Picture Books; Teaching Methods; Original Parent-child; Interaction

\begin{abstract}
Picture books as a new reading channel have multiple levels of meaning and influence. In recent years, picture books have become more and more popular in China. Inspired by the excellent picture books originally introduced from abroad, Chinese original picture books have also become increasingly prosperous. The indigenous picture books integrate Chinese traditional culture into this book form and push it into the public and into the world, which have played an effective role in propaganda. How to absorb and integrate based on the Chinese traditional culture and art is also the path to be explored for the development of domestic picture books. The teaching of picture books has far-reaching significance in the teaching of young children, but there are still some problems that need to be solved, such as the top-down teaching methods, the mode of thinking guidance and the one-sided teaching courseware. Although there are some problems in the development of the picture books in China, it still presents an overall upward trend in terms of original quality and market development. With the popularity of picture books, picture book creation may also be introduced into school teaching. People can utilize the rich resources of schools to provide more favorable conditions for the creation of original picture books, give full play to the advantages of native picture books, thereby create excellent picture books that are more in line with the local meaning.
\end{abstract}

\section{Introduction}

The picture book is a book including picture and words, which is different from independent pictures or literary works. The pictures in the picture book can express feelings as well as depict scenes. It is possible to use a single picture as an independent picture work or connect it to a complete story. Compared to traditional comics, it places more emphasis on the combination of picture and text and the practical meaning conveyed by it. In children's books, the picture book has many readers. The picture book not only provides children with interesting reading methods, but also allows adults to think more because of this reading method.

In recent years, the educational method of picture book reading has gradually expanded to a certain extent in the teaching of our country, and it is first practiced in kindergartens and primary schools in the form of class reading clubs. It is a relatively rapid period for the development of Chinese picture books from 2009 to 2011 as large number of foreign picture book resources are introduced by press in China. After this, the picture book market in China begin to show marked changes. In addition to e-commerce sales channels, libraries and picture books and other channels have also developed rapidly. Secondly, the new generation of parents has made a great change in their views on children's education and paid more attention to interesting emotional intelligence education. This is one of the reasons for the long-term development of picture books in China.

With the expansion of the picture book market, the original Chinese picture books also gradually reflect the unique local characteristics. A group of picture painters devote themselves to expressing their personal views on the real world with traditional picture language, and convey their confidence in Chinese traditional culture and folk art in an indirect way.

With the advent of the image age, the picture book art has gradually gained sufficient space for development in China, which actually should also prove a great change in the way of reading and development. The transformation of reader's own reading experience is precisely based on social 
and cultural background in which the picture book art is widely recognized.

\section{The Role of Picture Books}

The main readers of picture books are still concentrated in the scope of children for now. As a perfect combination of literature and picture, it plays a certain degree of influence on readers from different levels.

Improve Imagination. Not all children's imagination is born. Even with excellent talents, they still need good development and training to be fully utilized. The thinking modes of children under 6 years old enrich the growth experience through direct or indirect sensory stimulation, and imagination is gradually discovered in the accumulation of such experience. A good picture book has a good visual experience. Whether it is from the perspective of color or form composition, it can exert a subtle influence on a young child through the visual media, thus prompting the process of active imagination.

Expand Reading Range. Because picture books are full of storytelling and narrative and most of picture books have certain teaching significance in story selection, picture books will indirectly play a role in expanding the reading range. Rich reading links and appropriate reading materials can make children become the main body of reading, and at the same time, it also expand the creativity of reading subjects.

Enhance Interest. In the process of growth and cognition, our eyes become important information collectors due to the slowness of the development of comprehension ability. Ancients used to study hardly in order to pursue a rigorous learning process. In today's society where education is universal, such a boring and severe approach is obviously not applicable to everyone's reading. Therefore, it is particularly important to increase interest. The illustrated reading style of picture books greatly enhances the interest of reading, enabling readers to obtain both visual and textual information and deepen understanding.

Aesthetic Experience. Different from adults, young children will first use their existing life experiences to read picture books. In this process, children will place themselves in these situations and use their imagination to reinterpret this information to gain a new experience. Together with the hero of the story, they experience emotional changes and interesting stories in this novel world. This constantly updated aesthetic experience not only extends children's imagination space, but also further promotes the development of their thinking ability.

Promote Parent-child Communication. As the concept of parental education in China has gradually changed, parents pay more attention to communication with children in the education process and achieve mutual understanding through this exchange. Therefore, in the process of reading the picture book, parents often read together with their children. This process can enable both parents and children to enter the story together, to experience emotional changes and to achieve mutual communication and exchange.

\section{The Importance of the Development of Chinese Native Picture Books}

In the image age, the form of books, mainly based on pictures and supplemented with words, quickly became popular at the beginning of the century. Different from the traditional comic books, which are mainly based on text and supplemented by pictures, the modern picture book is more sophisticated about the continuity of the story, the interest of the painting and the sense of design of book binding. Modern picture books strive to attract readers' attention with visual language, make people's original reading experience produce profound changes, such as from the understanding of the semantics of the word to image analysis and induction.

Chinese native picture books are mainly divided into children's picture books and adult picture books. Especially in recent years, the development of adult picture books in China has become increasingly diversified. The emerging upsurge of image cultural reading has prompted the development of picture books. Under this promotion, a group of domestic painters chose to devote themselves to the creation of picture books, greatly enriching the forms and contents of Chinese 
native paintings, and at the same time expanding readers of picture books.

The modern picture books include both interesting pictures and complete stories. It not only brings more interesting reading methods to children, but also gives adults a new experience in reading books. At the same time, publishers begin to realize the importance of doing Chinese original picture books and strongly support the creation of local picture books. Among them, the most distinctive feature is the direct appropriation of traditional Chinese elements, such as ink, paper-cutting, shadow, new-year pictures and seal carvings. When these image symbols face the danger of being forgotten by the era of consumerism, the use of traditional aesthetic elements to promote traditional culture becomes understandable. Native original picture books have far-reaching significance through the use of traditional elements to indirectly convey the essence of national culture to young children.

\section{The Problems and Strategies in the Development of Picture Books Teaching in China}

In practice, picture book reading often fails to exert its real advantage due to the misunderstanding of knowledge, which makes picture book reading teaching often fall into various misunderstandings as following.

Wrong Teaching Methods. The picture book is mainly based on painting as people often understand things more deeply in the process of growth through visual information. However, some teachers use wrong teaching method in the picture book teaching. They use the simplified language of picture books for literacy training in reading.

Patterned Thinking Guide. Most teachers like to lead students to think about issues too much while guiding their children. Good picture books have exquisite paintings, which should bring children very sensitive visual feelings and color feelings. In essence, it is also an aesthetic training. However, teaching methods that focus only on teaching significance obviously lead to the modeling of students' thinking.

One-sided Teaching Courseware. One-sided understanding of picture book teaching is to combine pictures and texts to provide the most intuitive education for students. The reason for this problem is often due to the fact that the cooperation between the teacher and the multimedia courseware is too rigid. Some teachers rely on teaching courseware too much during the teaching process. The result of this approach will undoubtedly lead to one-sided teaching of picture books, and students will not be able to truly experience the fun of content.

Teaching Strategy of Picture Books. Focusing on the Visual Basis. The unique value of picture books is reflected in the appreciation of art and the improvement of aesthetics, not just the understanding of stories. Therefore, it is more important to use the visual basis as the focus of picture book teaching. The color, composition and form of the picture in the picture book are usually more in line with the characteristics of the child's psychological development. Such reading makes it easier for the reader to gain interest.

Cultivate Interest. Picture book teaching is not a story teaching. Cultivating students' interest is the key point of teaching. In the process of thinking and guiding, every discourse of teachers' understanding of personal experience will give students a certain amount of restraint. Therefore, teachers should master learning methods in the picture book teaching and help students to carry out in-depth and extensive thinking.

Interaction and Courseware Complement Each Other. Multimedia should be used as a teaching aid rather than a teaching leading in the picture book teaching. Teachers should pay attention to the rational use of picture books in teaching. Therefore, it still requires active interaction between teachers and students to deeply study the essence of picture book teaching. It is mainly based on interaction and supplemented by courseware. The full use of picture books is the fundamental way for the future development of picture books.

\section{Introducing Picture Book Creation into College Classrooms}

Modern picture books can often cause readers to resonate with emotions through rich painting 
language and compositional forms. Compared with simple text, the sensory experience brought by picture books is more interesting and full. Picture books gradually attract more and more adults or children's readers due to its easy-to-use and flexible design. With the increasing popularity of picture book teaching in the field of education, the exploration of "introducing picture book creation into university classrooms" has been gradually induced.

The parent-child picture book creation is operated in the form of production and application of picture books, which effectively uses intellectual resources in colleges and universities. At the same time, the advantages of preschool education and art majors are brought into play and the interest in picture book reading is enhanced through the integration of local features, landmark buildings and customs. Under the joint guidance of professional teachers and children field experts in colleges and universities, a set of teaching models that correctly read picture books have been developed in combination with college students of pre-school majors. It also contributes to the re-creation of picture book reading. Parent-child education mobilizes parents' enthusiasm and initiative. Chinese native picture book market must occupy the market share with excellent works and rich connotations. It also carries the important task of inheriting culture, allows children to contact more high-quality local parent-child picture books and has far-reaching significance for family education.

\section{Conclusion}

As a new industry, China's picture book industry is in a thriving stage of development. It provides more and more readers with interesting reading methods and parent-child interaction opportunities. In the context of fast-paced consumerism today, the traditional way of reading plain texts has been gradually neglected. Therefore, easy reading has become the preferred reading method for people living under great social pressure. In recent years, with the development of picture book market, picture book creation has gradually been introduced into colleges and universities. College resources can provide rich creative conditions for original picture books, so that people can create more Chinese original excellent picture books using the advantages of local elements.

\section{Acknowledgement}

Fund Project: Training Program to Innovation and Enterpreneurship of National College Students for Local Colleges and Universities in 2017, "Yolo" Parent-child Picture Book Art Center Project Number: 201711080005

\section{Reference}

[1] S. Z. Z. Gao (Japan) and X. Y. Wang. The Origin of Early Childhood Education. East China Normal University Press. 2014

[2] H•Rudolf•Schaeffer (USA) and L. Wang. Child Psychology. Electronic Industry Press. 2016

[3] Allard (Austria) and L. Liu. Educational Psychology of Children. Nanhai Press. 2015

[4] Y. T. Zhu. Educational Details. East China Normal University Press. 2015

[5] Eliot (USA) and Z. X. Guo. Art Vision Education. Zhejiang People's Fine Arts Press. 2016

[6] J. Dai. Contemporary Art Teaching Research. Yunnan University Press. 2008

[7] R. X. Sun. Love and Freedom. China Women Press. 2013

[8] Y. Q. Mo. Psychological Effects in Early Childhood Education. China Light Industry Press. 2017

[9] Kimmy. Kimmy’s Notebook. Dolphin Press. 2014

[10] L. J. Gan. Teaching Supervision in Colleges and Universities: Theory and Practice. Intellectual Property Press. 2018 